\section{A Spatial Translation on the Text of Raymond Queneau's "Exercises in Style"}

\section{Abstract}

\section{Purpose}

Founded in France in 1960, Ouvroir de Litterature Potentielle (OuLiPo Workshop of Potential Literature), is a literary game group that conducts experiments to improve creativity in the act of writing. The discoveries and inventions of the group in literature have also created an adaptable potential for non-literary fields. In this study, the work of Raymond Queneau Exercises in Style, one of the early works of OuLiPo, is translated into the medium of a different discipline. With this proposal, the study aims to make an external contribution to the creativity of disciplines which produce space.

\section{Design/Methodology/Approach}

The study uses an interdisciplinary approach to practice a translation process between the Oulipian literature and architecture. By exploring the possibilities of language with 99 variations of the same story, Exercises in Style establishes strong links with translation and

\section{Sırma Bilir* Pelin Yıldız}


creativity; it has been reproduced in many different fields and translated into different languages. In light of this source text, and its reproductions in many different disciplines, 33 variations of a space are produced.

\section{Findings}

With this study, space is redefined as a translation object and the potential of the spatial medium is examined with an Oulipian approach. This translation process shows lots of equivalent aspects between linguistic and spatial expressions. Beyond adaptation of the Oulipian techniques used in the text, new creative methods also come to the fore. Therefore, this productive game represents a potential for the educational environment of space design.

\section{Originality/Value}

The reproduction produced in this study is the first spatial translation of Exercises in Style. While being a sign of respect as trying to keep the original text alive, this translation can open the ways for the text's other adaptations for several scales of space medium or even different disciplines that have not been studied in this context yet. Furthermore, 33 variations of this space can be varied infinitely and this game can be continued as an open work.

\section{INTRODUCTION}

The space object is fed from many different sources in the design process, just like any other design product. The direct relationship between space and the ways of living makes space design-related disciplines unlimitedly crossing with other disciplines. This is an observable process together in the actions of designing and translating that the new is produced. Within its generally accepted definition, the product of design refers to a newly created object attributed as original; the translation product owes its existence to another source which is clearly displayed. However, one of the other points that can be noted in these two different definitions is that the design process acts together with different resources just as the translation process. Therefore, the designer does not start producing the new from the zero point just like the translator. Another point to highlight in this comparison is that the translator does more than simply repeating the source.

Imitation refers to a desire for understanding and learning, as well as the pleasure people get from establishing similarities. Rifat defines comprehending something by saying "having the power of potentially reproducing it" (Rifat, 2008, p. 54). The translator imitates the work written in one language into another. However, this imitation requires not only the meaning but also the formal figural elements of the text, as well as the distinctive style of the author. In other words, this means rewriting the elements which cannot be imitated, that is, recreating them. In summary, the process is to reproduce the work by changing the linguistic context of its existing content. 
This reproduction is defined by many translation theorists as an artistic activity involving a strong interpretation.

In the translation action, another remarkable point is the dialogue between two languages that translate to each other, beyond conveying the meaning. Grossman $(2010$, p. 27) reminds that a language has the potential to evolve only if it makes a connection with other languages. Wittgenstein ([1985] 2013, p. 133) draws attention to the importance of this dialogue, which is forcing the capacity of languages, by saying: "The limits of my language are the limits of my world". On the other hand, Benjamin and Derrida discuss this dialogue based upon the dilemma of "translatable" and "untranslatable".

Benjamin, in his text The Task of the Translator, points to a pure language while stating that languages are not alien to each other (Benjamin, [1923] 2002). According to him, the task of the translator is to give the pure language its freedom by rewriting the language, which is under the strong influence of another one. At this point, the translator breaks through the barriers of his own language for the sake of reaching the pure language; and every iteration of this act improves the language (Benjamin, [1923] 2002, p. 261). While defining well-written texts as translatable, he wants to reach unity without dominating the any of the languages and the dialogue they establish (Benjamin, [1923] 2002, p. 261).

Derrida, while expressing the idea of untranslatable, opposes to Benjamin's acceptance of the pure language. He emphasizes the impossibility of translation by specifying the transmission cannot be carried from one language to another in a pure and problem-free manner. Translation text can only be formed by disrupting the original language and shaking its roots. He argues that the meaning in the source language is impossible to fixate; he rejects the idea of originality in its essence, opposes the superiority of the original over translation (Derrida, 1985, p. 196). This argument of impossibility opens an inciting door for translation, unlike the negativity. ${ }^{12}$

In light of these thoughts, the definition of the translation act breaks free from its usual patterns and turns into a multi-layered tool of thought. The translation becomes free from being a mere copy that coming after original, rather it becomes a plurality that moves with it. The following sentences of Octavio Paz also support this plurality:

"Every text is both unique and a translation of another text. No text is entirely original, because directly itself is a translation in essence. It is performed first by transferring the world, which is out of words, to the world of words, and then a translation in the world of words. In the universe of words, every indicator and, accordingly, every sentence is the translation of another indicator
${ }^{1}$ Although the Myth of the Tower of Babel is a story mentioned in religious sources, it is often referred by translation theorists in terms of its relationship with translation. According to this myth, which has been repeated since the ages, the Tower of Babel is built by a community of people who speak a common language and have power of solidarity. But since the rise of the tower to the sky is seen as a resistance, it is destroyed by God and humanity is sentenced to translation by the mixing of their common language until that day. The "pure language" that Benjamin pointed out through the translatability symbolizes the collective power that humanity can grasp of the truth. The untranslatability emphasized by Derrida, on the other hand, symbolizes the desire that enforces the translation to reach this power with incompleteness of the tower.

\footnotetext{
2 While Benjamin draws attention to the aura and authenticity of the artwork in his text "The Work of Art in the Age of Mechanical Reproduction" many years later, he underlines that reproduction can take the original work far beyond its original position (Benjamin, [1982] 2018).
} 
and of another sentence. This proof can be reversed without losing its validity. Since every translation is different from each other, all texts are unique. According to this, each translation, to a certain extent, is regarded as an invention and creates a unique text" (Paz, (1971) 2012, p. 99).

The idea, referenced by the concept of translation, there is nothing that has not said or written before, is also expressed by the intertextuality theory put forward by Kristeva. With this concept she defined the permutation of texts, Kristeva argues that each new work is an endless re-reading of the previous (Kristeva, 1966). With a similar approach, Gerard Genette also proposes the Palimpsest theory he describes as hypertext. With this concept, which takes its name from reused parchment papers, he emphasizes the idea, that one text does not conceal the old text while overlapping, but on the contrary, it allows to show itself (Dillon, 2017, p. 17, 25, 27).

While suggesting linguistic studies as the basis of the research in non-textual areas in which human communication continues, Barthes claims that the concept of text cannot be limited with the field of literature, but all meaningful practices can produce a text (as cited in Aktulum, 2011, p. 13). This idea extends the translation activity beyond being a structure that is discussed only in textual/linguistic fields. Similar to this approach, besides intralingual and interlingual translations in the textual area, Jakobson suggests the concept of intersemiotic translation (Jakobson, [1959] 2012, p. 62).

The idea of intersemiotic translation makes it possible to translate between the two areas (disciplines) that are completely different from each other; and creates a legible frame where the translation approaches the design activity, although it makes us rethink about the limits of translatability/untranslatability. At this point, while the intersemiotic translation seems to be a very difficult process, it also approaches to the lean transformation activity like the act of thinking naturally develops.

Portzamparc expresses the adaptability of the intertextuality theory for the spatial environment by remarking that "one space always responds to another space" (Portzamparc \& Sollers, 2014, p. 94). On the other hand, it is possible to extend this idea by saying, space always responds to another text or work of another discipline.

The translation activity between two different fields, including architecture, was first mentioned in the exhibition titled Deconstructive Architecture, curated by Mark Wigley and Philip Johnson in 1988 (Johnson \& Wigley, 1988). With this step, a wide translation movement started, which includes many architects, from Derrida's deconstructive philosophy to the spatial production environment. In this translation act, as suggested in 
the essence of deconstruction "there is no hygienic starting point between architecture and deconstruction and they work together simultaneously" (Wigley, 1989, p. 9). While deconstruction architecture exists with the basis it gets from the deconstruction philosophy, the idea of deconstruction also finds itself an opportunity to survive by opening itself to another structure in architectural environment in which it is translated. On the other hand, Esra Akcan, studying Turkish-German relations through the urban and residential architecture, interprets the relationship which has established by architecture between different spaces as an act of translation (Akcan, 2012). Akcan addresses modern architecture through the cultural and political aspects of the translation and studies it with intertwined indicators between two sides. In a manner far from its hierarchical structure, which is frequently criticized, in this relationship, it is dominated by the mutual nurturing of both sides through translation and the emphasis on hybridization. Akcan's interpretation on the fidelity-infidelity relationship in the translation of architecture is an important reference about the structure of the design process:

"If there could ever be anything like an ultimate transformation during the act of translation in architecture, which there could not, it would be when absolutely no source could be detected in the work. If there could ever be anything like no transformation during the act of translation, which there could not, it would be the case when the identical conditions are attained in the places of departure and arrival" (Akcan, 2012, p. 8).

In light of these discussions, this study aims to make an external contribution to the content of the disciplines which produce space with the translation from literature, a completely unrelated field to space design. In this context, the texts of the OuLiPo Group, which establishes connections between the concepts of creativity and translation, provides an area that encourages translation for various disciplines for having a creative side. In this study, a spatial translation was produced from the text Exercises in Style written by Raymond Queneau, one of the early works of OuLiPo. In other words, this work has been reproduced in a spatial medium, in the light of its adaptations in different fields, which can be considered as intersemiotic translations.

In the production techniques of the OuLiPo group, while trying to develop creativity in the act of writing, translation action is approached from a different aspect. The group's perspective brings the reproductive and creative sides of translation to the forefront. On the other hand, in OuLiPo productions, there is the idea that creativity can be revealed by acting with constraints instead of unlimited freedom. In all these aspects, the attempt to 
3 The first members of the group were the names like Jean Lescure, Jacques Bens, Noel Arnaud, Paul Braffort, Stanley Chapman, Marcel Duchamp, Ross Chambers. The members who joined the group later can be listed as Jacques Roubaud Marcel Benabou, Italo Calvino, Michelle Metail, Michelle Grangaud, Harry Mathews, Oskar Pastior, George Perec, Jacquet Jouet. The last members to join the group are Ian Monk, Anne Garetta and Oliver Salon (Consenstein, 2002). reproduce Exercises in Style, which is an Oulipian work, with a spatial translation, is a process that brings space, translation, and creativity together. Therefore, the purpose of this study is an attempt to search for the potential of spatial production in OuLiPo's player attitude, by defining the space as a translation object and by pushing its limits.

\section{OULIPO}

OuLiPo is a game club founded by a group of friends ${ }^{3}$ from different disciplines in 1960 in Paris, in the leadership of Raymond Queneau, a literary artist who is interested in mathematics, and François Le Lionnais, a mathematician who is interested in literature. The name OuLiPo, (Ou-Li-Po), consists of the abbreviations of "Ouvroir de Litterature Potentielle", Potential Literature Workshop.

When the word literature comes together with the word potential; a hidden and unknown future is pointed out that has not yet existed for literature. The word ouvroir means workshop (atelier) primarily, and at the same time, in French, means workplace in which women make handicrafts, such as sewing, embroidery and so on, for charity. It is meant an environment where the potential of literature is studied and cut out (Akdağ, 2010 , p. 29). On the other hand, it has a sense that Oulipo's discoveries and inventions are open for anyone (Mathews \& Brotchie, 1998, p. 202).

According to the Oulipians, creativity is revealed by being triggered by constraints, in contrast to what is thought in the classical sense. At the workshop which members established, try to find new values not yet discovered in literature, by introducing constraints to the content of the act of writing. Mathews (2005, p. 97) states that OuLiPo offers games for authors to play. He points out that, a game is defined "with the bother of following the compelling and perhaps impossible rules, people find themselves reacting beyond imagine by their capacity and in a trance of some sort" (Mathews, 2005, p. 98). He states that the things that revealed with this way, which are necessary to reach the goal, are noticed later. Paul Fournel supports this by pointing, when you are restricted, you can find a new path by another side (Özen, 2005, p. 78).

Oulipian constraints are the ones created by the authors, but outside from the text, also not related to its own content, in a sense the constraints that are foreign to the text. Raymond Queneau defines Oulipians as "rats who must build the labyrinth from which they propose to escape" (Motte, 1998, p. 22). The negative meaning evoked by the state of limitedness triggers creativity for the Oulipians and begins to be part of an arbitrary situation. According to Ekici, "the material of this creativity is not 
characters, stories, situations, emotions; but is words, letters, that is, the formal elements of writing" (Ekici, 2016, p. 49). The products created by the restrictions that must be complied with sometimes make the expression strange and alien; It enables the production of unique and hybrid texts in which absurdity and funny can be felt.

Techniques produced in the workshop environment, defined as a research laboratory of OuLiPo, are collective works applied as short exercises. These techniques are method recommendations for experiments in which the results are unknown. When a constraint is set, it opens another way to a new one. The interconnected structures of the techniques provide a fertile potential which is endless and constantly triggers each other.

Oulipians, as both technically and literary, associate the memory with their production, as part of their theoretical approach (Consenstein, 2002, p. 45). In this sense, for OuLiPo techniques, Queneau talks about a dual production method which looks both backward and forward (Viers, 2008, p. 34). Le Lionnais emphasizes the importance of memory and of survival for Oulipo and expresses the concepts of "anoulipism devoted to the exploration and synthoulipism devoted to the invention" (Motte, 1998, p. 2). One is analyzing the experiments from past structures; the other is to develop methods that have not yet tried before with an approach of synthesizing the facilities of these methods and turns them anew. Similarly, George Perec defines his production as experimental and quotational, a jigsaw kind of literature (Perec, 2003, p. 68-72).

While Oulipians develop their constraints from the idea of literature can be made in any way and can be fed from any field, they research a way for transfer the technology especially between mathematics and literature. The text named Cent Mille Milliards de Poemes (One Hundred Thousand Billion Sonnets) written by Raymond Queneau in 1961, triggered the establishment of OuLiPo as one of the pioneering works that gave the first idea of how the relationship between mathematics and literature can be established (Mathews \& Brotchie, 1998, p. 14). Queneau writes a text consisting of 14 sonnets in total, each of which has 10 strings, and cuts each string of this work, which he interferes like an object, to form horizontal strips. Thus, each string of each sonnet can turn as pages that can be translated separately and can interact with each other (see: Figure 1,2). Eventually, a combinatorial work arises in which each reader can create his own poem (Motte, 1998, p. 4). 
Figure 1. Image from the book (Queneau / One Hundred Thousand Billion Sonnets, 1961).

Figure 2. Image from the book (Queneau / One Hundred Thousand Billion Sonnets, 1961).

\footnotetext{
${ }^{4}$ Lipogram: It is a writing technique in which the use of a selected letter is restricted (Mathews \& Brotchie, 1998).
}

5 Barthes's text, The Writer's Death, supports this consideration between the author and the reader (Barthes, 1989).

6 OuLipoPo (Potential Detective Literature) (1973), OuPeinPo (Potential Painting Workshop) (1980), OuMuPo (Potential Music Workshop) (1980), OuBaPo (Potential Comic Book Workshop) (1992), OuCuiPo (Potential Cookery Workshop) (1990), OuHistPo (Potential History Workshop) (1993), OuMathPo (Potential Mathematics Workshop), OuPhoPo (Potential Photography Workshop) (1995), OuTraPo (Potential Tragicomedia Workshop) (1990), OuArchPo (Potential Architecture Workshop) (2001), OuPolPo, (Potential Politics Workshop) (2001), OuGraPo (Potential Graphic Design Workshop) (2001), OuGraPo (Potential Grammar Workshop) (2002), OuBrekPo (Potential Breakfast Workshop) (2015) (Elkin \& Esposito, 2013)., OuLciPo (Potential Literary Criticism Workshop), OuCarPo (Potential Cartography Workshop), OuGeoPo (Potential Geography Workshop), OuOuPo (Potential Metaoulipo Workshop), OuTypPo (Potential Typography Workshop), OuLitramuPo (Potential Traditional Music Literature Workshop), OuJaPo (Potential Gardening Workshop), OuPoliPo (Potential Polish Literature Workshop), OuWiPo (Potential Wikipedia Workshop), OuMyPo (Potential MySpace Workshop.) (Becker, 2012).
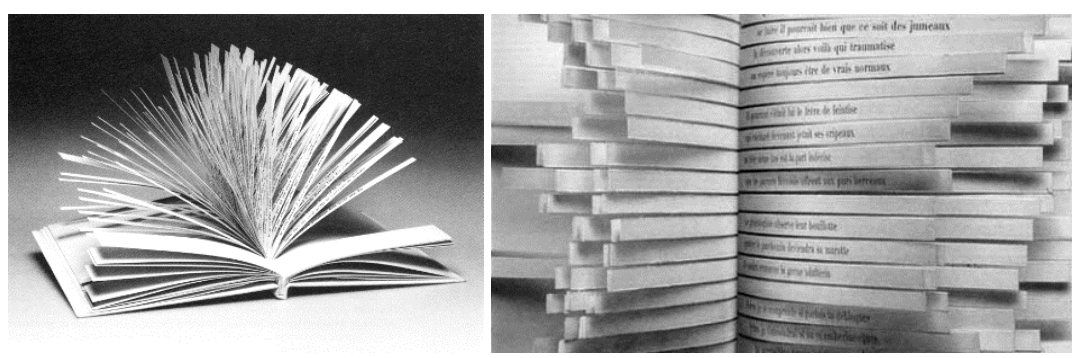

In addition to short experimental texts where techniques are tried, Oulipian novels are also produced. Perhaps the one which is the most known of these is George Perec's novel named $L a$ Disparition (A Void), written in 1969. In this novel, Perec applies the Lipogram 4 technique and writes the text without using the letter "e" which is the most used in French. It is especially remarkable that critics did not realize that the text was written under this constraint at the time of its first publication.

As the constraint behind the writing action opens up to the reader like a riddle, a bilateral game occurs. This playful situation is transparent in some works and hidden in some and expects to be discovered by the reader. This returns the reader's passiveness to an active position and in a sense, provides encouragement for rewriting what is read. 5

\section{OUXPO}

Le Lionnais introduces an Ou-X-Po model in OuLiPo's manifesto, by describing all kinds of creative activities, which are reproducible infinitely, with the expression "x" (Mathews \& Brotchie, 1998, p. 320). The idea that a potential workshop may have a counterpart in any discipline that comes to mind, relates to creativity, makes it possible to turn OuLiPo by itself into other disciplines. In this way, OuLiPo keeps up to date while spreading to other areas, it also opens the way to intersemiotic adaptations of its techniques. Some of these workshops are very productive, some remained only by the proposal as an Oulipian game. ${ }^{6}$

All OuXPo workshops, just like OuLiPo, act as experimental laboratories that try to explore new techniques, far from the intention of producing a work of art. The first example of Oulipian techniques begins with OuPeinPo (Workshop for Potential Paint) (1980), especially with trials in a visual environment. OuLiPo's previous structures, techniques akin to taking old texts and transforming them with several interventions can also be witnessed in OuPeinPo. With mechanical interventions such as cutting to existing images, replacing the position of the parts, changing ratios, the meaning of the image is also transformed besides its shape (see: Figure 3). With these morphological games, new possibilities are tried to be discovered. 

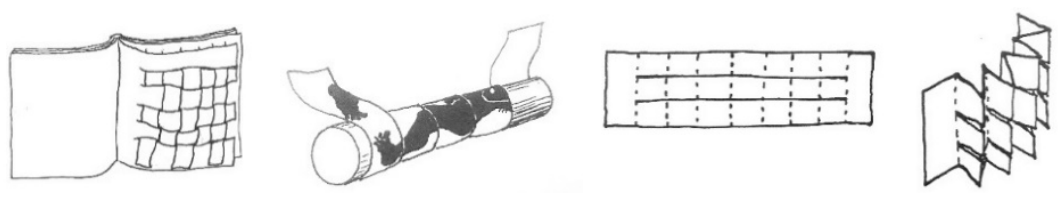

The natural relationship between music and mathematics creates significant potential for another OuXPo initiative, OuMuPo (1980) (Workshop for Potential Music). The fact that the notes, which are the composing tool of music, corresponding with the sound is in parallel with the letters also essentially correspond with the sound. Therefore, both language and music are structures that emerge through sound and made sense of those who perceive it. Concordantly, in Oulipo's translation to OuMuPo, some of the OuLiPo's constraints are tried on musical studies (Mathews \& Brotchie, 1998, p. 329). One of these works is the solo piano work that Christopher Hobbs adapted the lipogram technique on notes instead of letters.

OuBaPo (1992) (Workshop for Potential Comics), which associates comics with OuLiPo techniques, is one of the considerably productive workshops. It is also meaningful that this group was founded after OuPeinPo, since OuBaPo studies created a kind of narrative that combines textuality and visuality. The works of OuLiPo and OuPeinPo together become a resource for OuBaPo. Becker likens OuBaPo to "OuPeinPo's young and cool cousin" (Becker, 2012, p. 268). Many OuLiPo techniques have an easily adaptable potential for narrative strings in comic books (see: Figure 4,5). One of the significant examples is Gilles Ciment's work (see: Figure 6) that Herge redraw a 62-page Tintin adventure in 1997 using 6 non-speaking frames (Becker, 2012, p. 269). The re-framing technique becomes a translation for the comic book for converting to $\mathrm{Haiku}^{7}$, which is one of the techniques that Oulipians use.
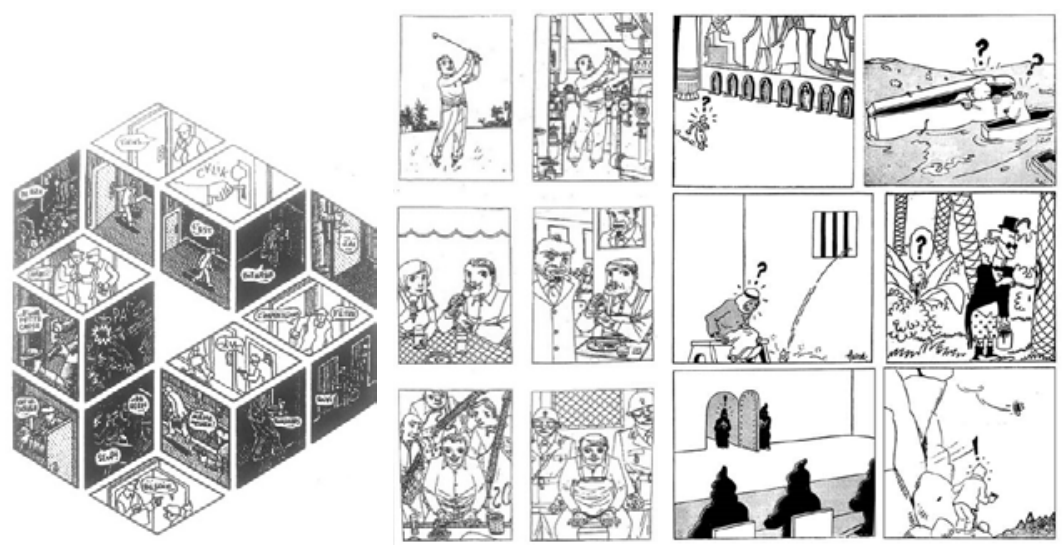

Considering Oulipo's counterpart in the architectural medium, it can be mentioned that the space, like literature, allows
Figure 3. Studies on the manipulation of the paper surface. (Mathews \& Brotchie, / OuLiPo Compendium, 1998).

7 The process of turning a poem into Haiku, a Japanese poem consisting of divided 17 syllables as to be 5-7-5. It was used as an abbreviation method by Oulipians (Mathews \& Brotchie, 1998, p. 153).

Figure 4. An example of a narrative type created in accordance with the multiple reading method. The novel allows to be read in 3 different ways (Mathews \& Brotchie, / OuLiPo Compendium / 1998).

Figure 5. An example of a narrative type, in which a particular visual repeats, but the content changes (Mathews \& Brotchie, /OuLiPo Compendium, 1998).

Figure 6. Gilles Ciment's Cigares du pharaon (Mathews \& Brotchie / OuLiPo Compendium, 1998). 
interdisciplinary transitions, as well as it establishes an intense relationship with mathematical structures. In addition to the fact that mathematics naturally affects architecture, it is necessary to mention the normality of the restrictive structure in the content of the space design process. Having introduced OuLiPo's relationship with architecture, Read has suggested that all architecture has as much potential as literature and stated that every project has its potential reading (Read, 1998, p. 192). According to him, in architecture, a constraint is continuous, but this limitation is what makes architecture meaningful (Read, 1998, p. 194). In addition, Read underlines that OuLiPo's tendency to use traditional structures is also valid for architecture (Read, 1998, p. 192). The structure of OuLiPo focuses on the craft of writing, for which the purpose is to search for potentials contrary to producing finished works, corresponds to exercises to increase imagination for architecture. In this context, Read produced a translation of Queneleyev's Table ${ }^{8}$, (see:

8 Queneleyev's Table was produced by Raymond Queneau to explain the application of Oulipo techniques, with the relationship that formal items on the vertical axis have with semantic elements on the horizontal axis. The name of the table was made up by combining the names of Queneau, and Dimitriy Mendeleyev, who is the creator of the Periodic Table in Chemistry. This table has been reproduced by many other OuXPo members for their own disciplines (Mathews \& Brotchie, 1998).

Figure 7. Adaptation of the Queneleyev's Table produced with regarding restriction techniques in architectural disciplines (Read, 1998).
Figure 7) intended to architectural disciplines which expresses application logic of the techniques in OuLiPo (Read, 1998, p. 193).

\begin{tabular}{|c|c|c|c|c|}
\hline $\begin{array}{l}\text { Constraint by: } \\
\text { Constraint of: }\end{array}$ & Number & Dimension & Form & Nature \\
\hline Material & $\begin{array}{l}\text { Design with given } \\
\text { amounts of given } \\
\text { materials (c.g. } \\
\text { design a shelter } \\
\text { with a single } 4 \times 8 \\
\text { sheet of plywood) } \\
\text { Join two materials }\end{array}$ & $\begin{array}{l}\text { Tiling Patterns: } \\
\text { Cut a pattern with } \\
\text { no waste that will } \\
\text { recombine in various } \\
\text { ways } \\
\text { Design with } \\
\text { repetitive units of a } \\
\text { single material }\end{array}$ & $\begin{array}{l}\text { Standardizedbuilding } \\
\text { components } \\
\text { Erector Set } \\
\text { Constructions } \\
\text { Kit of Parts }\end{array}$ & $\begin{array}{l}\text { Design with one material } \\
\text { (eg. wood construction) } \\
\text { Constructional } \\
\text { Expressionism } \\
\text { Handworkpractice } \\
\text { (Bauhaus Craft Studios) }\end{array}$ \\
\hline $\begin{array}{l}\text { Detail or } \\
\text { Element }\end{array}$ & $\begin{array}{l}\text { Using given } \\
\text { elements in } \\
\text { composition: } \\
\text { Collage/Bricolage } \\
\text { Design one detail } \\
\text { within a given } \\
\text { composition }\end{array}$ & $\begin{array}{l}\text { Redundant elements } \\
\text { Repeating Rhythms } \\
\text { Overlay of rhythms }\end{array}$ & $\begin{array}{l}\text { Classical Ornament: } \\
\text { Codified omamental } \\
\text { palatte } \\
\text { Substitution of } \\
\text { materials in an } \\
\text { element of fixed } \\
\text { dimension. } \\
\text { (Transformation of } \\
\text { textile weaving into } \\
\text { masonry patterns - } \\
\text { Semper) } \\
\text { (Origins of classical } \\
\text { details in wood } \\
\text { building technioue) }\end{array}$ & $\begin{array}{l}\text { Single intention in } \\
\text { Detailing (eg. Modern } \\
\text { details to make clean } \\
\text { lines) } \\
\text { Functionalist Design }\end{array}$ \\
\hline Composition & $\begin{array}{l}\text { Limit to one } \\
\text { compositional } \\
\text { device (Bauhaus 2- } \\
\text { D and 3-D } \\
\text { exercises) } \\
\text { Adapting a spatial } \\
\text { structure (eg. } \\
\text { variations on the } \\
\text { grid. FLLW) } \\
\end{array}$ & $\begin{array}{l}\text { Classical } \\
\text { Proportions } \\
\\
\text { Design within } \\
\text { dimensional limits } \\
\text { (railroad sleeping } \\
\text { compartment) }\end{array}$ & $\begin{array}{l}\text { Classical Propriety: } \\
\text { Formal rules for } \\
\text { building according to } \\
\text { social role. } \\
\text { Building Typology: } \\
\text { Rowhouse, Ranch } \\
\text { House, bungalow }\end{array}$ & $\begin{array}{l}\text { Demonstration houses: } \\
\text { building as idea } \\
\\
\text { Design to address a } \\
\text { specific phenomenon } \\
\text { (Design a natural light } \\
\text { fixture) (James Turrell) }\end{array}$ \\
\hline Situation & $\begin{array}{l}\text { Locate a given } \\
\text { object in a given } \\
\text { context. (Using } \\
\text { mass produced } \\
\text { elements in an old } \\
\text { city) } \\
\text { Place a brick on the } \\
\text { ground (Gregotti) }\end{array}$ & \begin{tabular}{|l|} 
Minimum \\
intervention to \\
change composition \\
of city \\
Design of \\
Infrastructure. (Put a \\
highway (of given \\
dimensions) into a \\
city
\end{tabular} & $\begin{array}{l}\text { Design from outside } \\
\text { in: } \\
\text { Building as detail of } \\
\text { city. (Gregotti) } \\
\text { Urban Design } \\
\text { Guidelines }\end{array}$ & $\begin{array}{l}\text { Extension of project into } \\
\text { city. } \\
\text { Design to address an } \\
\text { urban quality ( } \mathrm{e} . \mathrm{g} \text {. } \\
\text { juxtaposition of scales of } \\
\text { movement: highways in } \\
\text { the city) }\end{array}$ \\
\hline
\end{tabular}


Although it seems that Group OuArcPo (Workshop for Potential Architecture) was founded in 2001 (Elkin \& Esposito, 2013), this group did not present any activity. Independently, Levent Şentürk founded the PoMi ${ }^{9}$ workshop with its Turkish name in 2002. The activities of this group, which has been continuing since 2002, take place with a dynamic student group at the Faculty of Architecture of Eskişehir Osmangazi University. Among the experimental works performed, the adaptations of some Oulipian techniques for the spatial environment can be seen, and some principal Oulipian works are effective on the productions of the group (see: Figure 8). In this sense, it can be said that the craft factor, which can be observed in the definition of OuLiPo and the works it produces, is emphasized especially also in the architectural adaptations of PoMi.
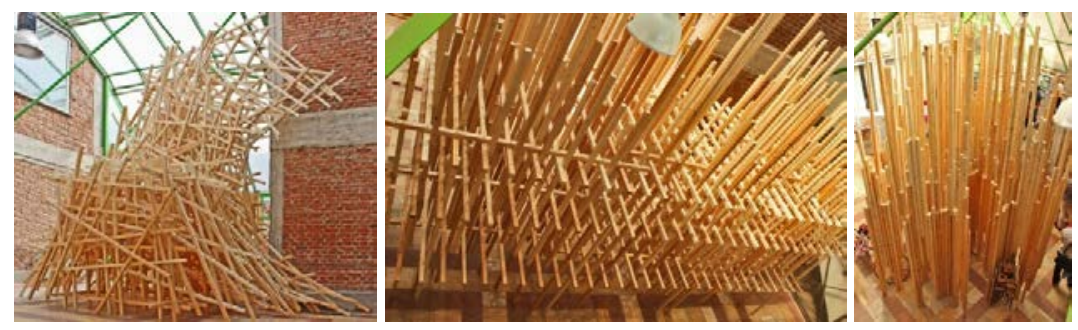

\section{EXERCISES IN STYLE}

Exercises in Style (Exercices de Style) is a cult book written by Raymond Queneau in 1947 before OuLiPo was founded, which could be called OuLiPo's prototype. The text, unlike a classic narrative that begins and continues linearly, consists of 99 different repetitions of a same simple story.

The aim of Queneau to write this experimental text is to query the possibilities, limits, and potential of his language, French. He makes 99 separate translations in a sense with the claim that how different a story can be repeated, and each translation is a language exercise in which a different style is tired.

The rather ordinary and insignificant template story ${ }^{10}$ in the text makes no sense when it is read apart. Entirety created by all variations together shows the purpose of the work. Each variation supplements each other. Queneau's use of such a story is a conscious decision. The neutrality of the story turns the whole of the text into a catalog in a way, creating an encyclopedic effect, even bringing it closer to a grammar book. Şentürk interprets Exercises in Style as "a kind of domestic flight route map or a Burda sewing pattern" (Şentürk, 2004, p. 393).

This experimental text then becomes an early source for the lab in which OuLiPo's experiments are executed. The insignificancy of the content gives the feeling that another template may be possible to remove and replace the story in the text and, in a sense, opens the way for its adaptations. Each variation has a
9 Pomi's (Potential Architecture Workshop) activities, continuing with many architecture students since 2002, have been published as a book in 2012 (SSentürk / POMI: Potansiyel Mimarlık İșliği: Bir Tasarım Stüdyosunun On Yılı (20022012), 2012).

Figure 8. One of the structural experiments in PoMi, inspired by Oulipo techniques, where certain themes are expressed with a limited number of wooden bars (Şentürk, 2016).

10 In the story mentioned in the text; a tall and capped young man a young, long necked and capped man takes a bus in Paris. The young quarrels with one of the passengers as he disturbs him each time a new person gets on the bus, and then he sits in a vacant place. Two hours after than this event, the same young person is seen again in front of the Gare Saint-Lazare. He talks to a friend next to him about the button of his coat. 
title. This indicates the theme, style, and hence the constraint under which it is written. Most titles in the text are the first examples of Oulipian techniques.

The number 99 can be seen as a symbol that makes association with mathematics and indicates exaggeration. On the other hand, this indicates even the variation can continue forever, the text may end only on a stoppable point. Queneau explains his decision by commenting "neither too little nor too much" (Queneau, [1958] 1998, p. 4). Also Umberto Eco, comments, "If the text consisted of only 10 exercises instead of 99, it would be less fun, or similarly if it consisted of 99,000 instead of 99, although maybe a little more tiring, it would have been even more fun " (Eco, 2013, p. 12).

The title of the entire Exercises in Style gives important clues about the text. Goto points out that the word "exercise" gives reference to three different areas, the concepts of school, music, and mind (as cited in Akdağ, 2011, p. 4).

Apart from the relationship between practice and repetition with translation, another concept that they refer to is education. Repetition is one of the ways to learn. In mathematics, grammar, music, plastic arts, sports; hence, in many disciplines and in every field that requires skill, repetition is applied with the desire to get experience and reach perfection. The relationship of Exercises in Style with music evokes the pleasure emerging with repetition. Recurring forms in music are an important starting point for this work.

\section{THE TRANSLATIONS OF EXERCISES IN STYLE}

It is known that, when writing Exercises in Style, Queneau got inspired by a concert in which Bach's Fugue Art played in the 1930s. The repeating as if going to eternity, forms of the music influenced Queneau and encouraged him to explore if he can create a similar work in the field of literature (Mathews \& Brotchie, 1998). In this regard, both before and after, Exercises in Style can be read as a palimpsest, based on the relationship it established with productions in literary and other fields. It can be said that the work has embodied by being published, but in a sense, the writing process has never ended, and continued as an open work.

The translation of a text that is multiplying the layers of a classic text and moreover basing its writing on formal limitations, requires taking the challenges of OuLiPo games in the same way. This equates translation with rewriting. Le Tellier emphasizes that each OuLiPo translation is also an Oulipian practice by particularly rejecting the hierarchy between the original and the translation (Viers, 2008, p. 37). Mathews also points out that for translators of OuLiPo texts, the translation from one language to 
another is also a kind of writing constraint separately from the constraints of the original text (Symes, 1999, p. 99).

As an experiment that inquires the possibilities of the original language, Exercises in Style pushes the limits of French. Therefore, the relation of the text with the structure of French is in a tightness that is difficult to loosen up. This, in a sense, makes it almost impossible to translate the text into another language. Despite all the difficulties, the translation of the text was actualized in a total of thirty-seven different languages under the influence of a provocation. Every translation reveals the desire to test the limits and possibilities of the translated languages through this exercise, beyond the conveying of the story repeated in the text to another language.

The first inter-language translation of the text was made into English in 1958 by Barbara Wright. In the preface to the 1998 edition of his translation, Wright states her first opinion to the idea of translating the text, which is, "as untranslatable as the smell of garlic in the Paris metro." Over time, her opinion changes, and begins to think that "the language in which the work is written is unimportant, just as the story in it." (Queneau, [1958] 1998, p. 16). Later on, when translating the work, Wright did not want to take all the responsibility by herself, for the translation of an exercise that she had difficulty. She states that she consulted Queneau, but when Queneau says that he would not able to give her advice on this, she realized the meaninglessness of her expectation (Queneau, [1958] 1998, p. 16).

Umberto Eco, who translated the text into Italian in 1983, also emphasizes at first that it seems impossible to translate Queneau's exercises literally. According to him, "to transform completely these jargons, forms of speech and situations that contain a social context and time specific to France and Paris, is a so-called attempt. None of the intertextual and historical relations can be completely isolated from the soul of the French language, in which they are written" (Eco, 2013, p. 14). On the other hand, Eco states that, while translating Exercises in Style into their own language, both he and Wright were reproducing the text in another social, historical and intertextual context. Because, according to Eco, these are not the main issues revealed by the text (Eco, 2013, p. 14).

The first attempt to translate Exercises in Style into Turkish was realized by Ferit Edgü. As he stated in the preface of the book Yazmak Eylemi (The Act of Writing) published in 1980, that he started to translate Exercises in Style in order to make wording practices in his own language; however, he predicted that his effort would fail as the translation progresses (Edgü, 2015, p. 7). Edgü also predicted the possible losses for the translation of this 
text, which is based entirely on puzzles and word games. By stating that he preferred to try such research within the possibilities of Turkish, he left his initial translation halfway (Bozdemir, 2018). In this way, Edgü produced a different story than Queneau wrote and repeated it with 101 variations.

In 2003, Armağan Ekici produced the Turkish translation of the text under the name of Biçem Alıştırmaları. Beyond making Exercises in Style accessible in Turkish, this translation is also a pioneering text for trying Oulipian writing techniques in Turkish. By his experience from this translation process, Ekici states that "the obligation to comply with a certain formal limitation is a liberating power that removes all other limitations and breaking the deepest and strongest restrictions that the author put, in order to write with his own voice" (Ekici, 2016, p. 46).

In addition to the translations of the text into other languages, there are also many other translations with different adaptations where fidelity is reduced. Similarly, to Edgü's book, where he variated his own story, Gökdemir İhsan made 33 variations in different types in 2010 (İhsan, 2017). While the main content of the story remains constant in this text titled Kurmaca Alsştırmaları (Exercises in Fiction), the types of fiction vary. In 2013, Bethany M. Brownholtz reproduced Exercises in Style in a temporal context (Brownholtz, 2013). In this translation, with 40

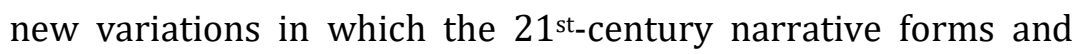
techniques are used, the variations written in 1948 are adapted to the language of today with a kind of parody (see: Figure 9).

Figure 9. Variations titled Text Message, Tweet and Facebook Status Updates from the study (Brownholtz, 2013).
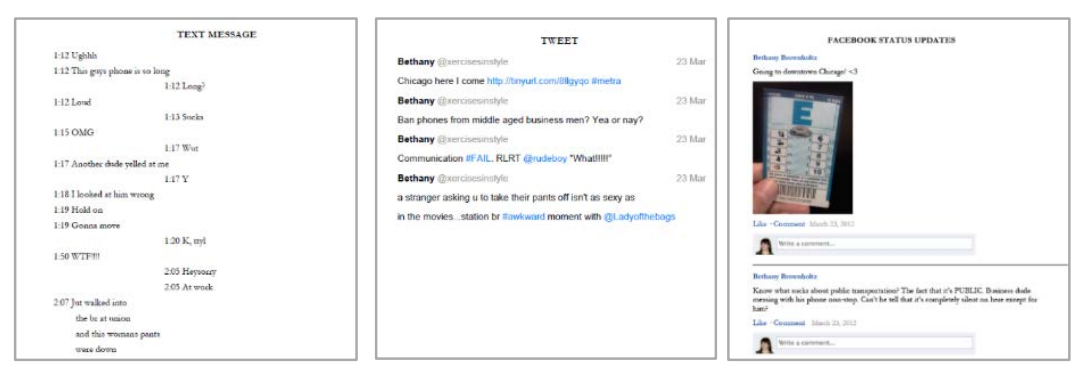

The first adaptation, in which the work is transferred to the outside of the textual medium, takes place with an audiobook published by French actor Yves Robert in 1954. With this work, how the text continues its impact when it is voiced, and the unique style variations of the audio performance have been tried (see: Figure 10). Based on this translation, similar adaptations were also made for the theater (see: Figure 11). OuLiPo's unique playful and absurd items are transferred to various plays named Exercises in Style. The effects of the constraints in the stage on the creativity of the actors and the play are experienced. 

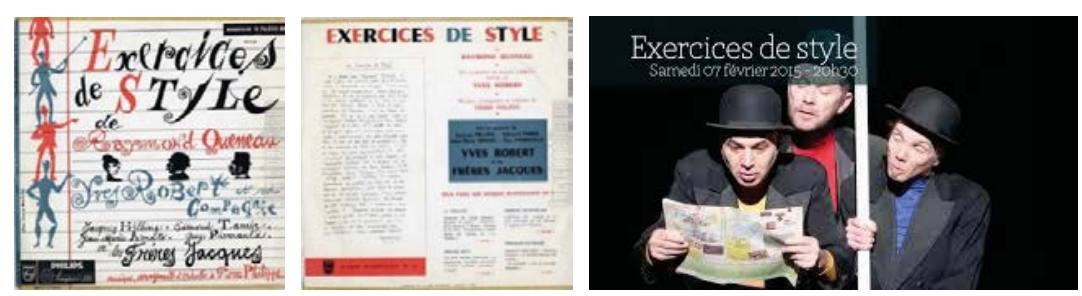

Visual/formal areas are the most common in the adaptations of Exercises in Style to mediums outside the literary field. Book covers (see: Figure 12), which express summarized visual translations of texts, provide clues for intersemiotic translations produced in this context.
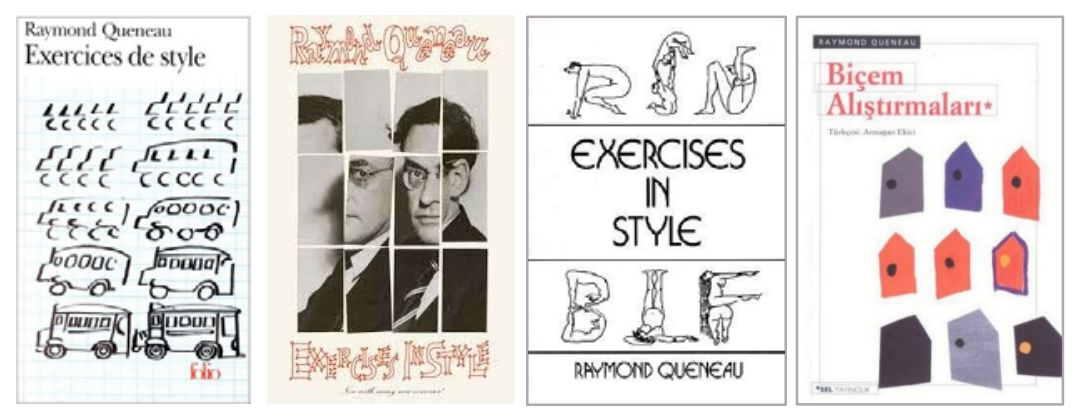

Visual variations were added to the new editions of Exercises in Style over time. One of them is the illustrations made by the OuPeinPo member Jacques Carelman, added to the 1963 edition (see: Figure 13). Another series of visual variations is a special production edition prepared by designer Robert Massin and illustrator Jacques Carelman together. In print, 99 variations are reinterpreted, with typographic characters designed by Massin. 45 variations that follow were accompanied by Carelman's illustrations. The series with drawings, photographs, collages and 3D narratives led up the visual translations that were produced later (see: Figure 14).

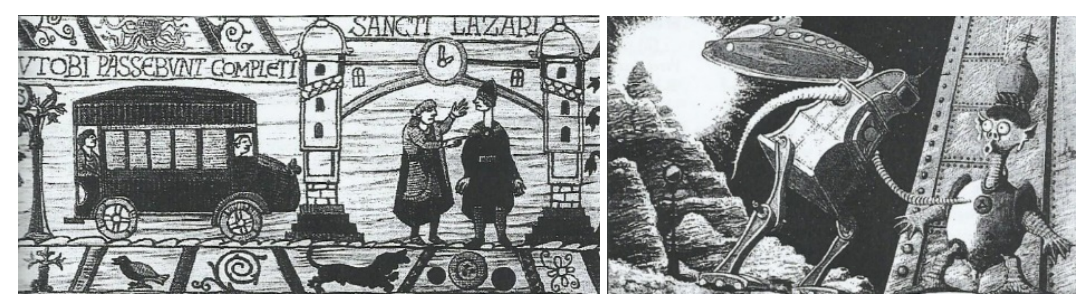

Figure 10. Examples from the record covers of Yves Robert's Exercices de Style audiobook (URL1).

Figure 11. Example of poster of the theater plays (URL2).

Figure 12. Examples of French, English and Turkish book covers (Queneau / Exercices de Style, 1947), (Queneau / Exercises in Style, 1958), (Queneau / Exercises in Style, [1958] 1998), (Queneau / Biçem Alıştırmaları, [2003] 2010).

Figure 13. Jacques Carelman's illustrations from 1963 edition (Mathews \& Brotchie / Oulipo Compendium, 1998). 
Figure 14. Examples of cover and pages from the book (Queneau, Massin \& Carelman / Exercises de Style, 1963).

Figure 15. Swarte / Raymond Queneau: Exercises de Stle \# 100, 2008 (URL 3).

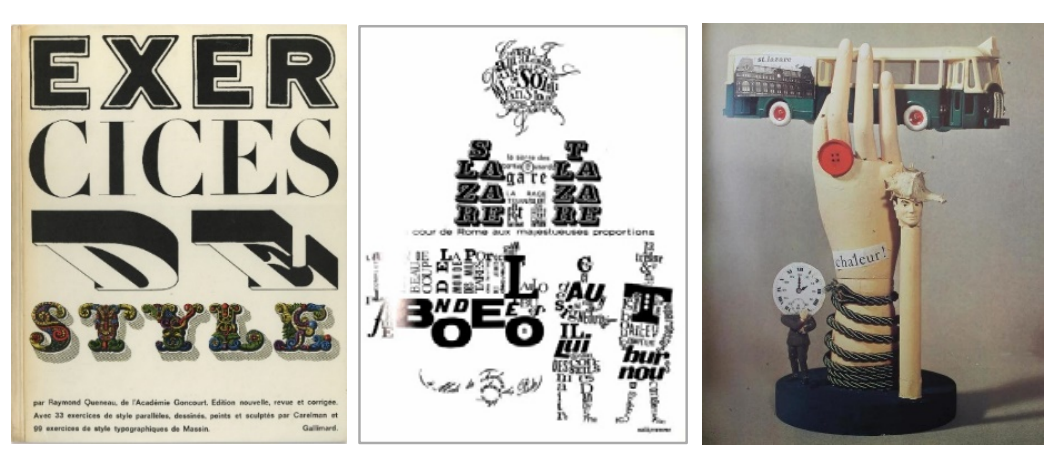

Architect and graphic designer Joost Swarte, one of the illustrators of New Yorker magazine, was involved in these visual translations with an illustration published in 2008 (see: Figure 15). Swarte, by drawing the story of Queneau in his language, replied with the 100th variation he added as a reader to 99 exercises (Moors Magazine, 2019).
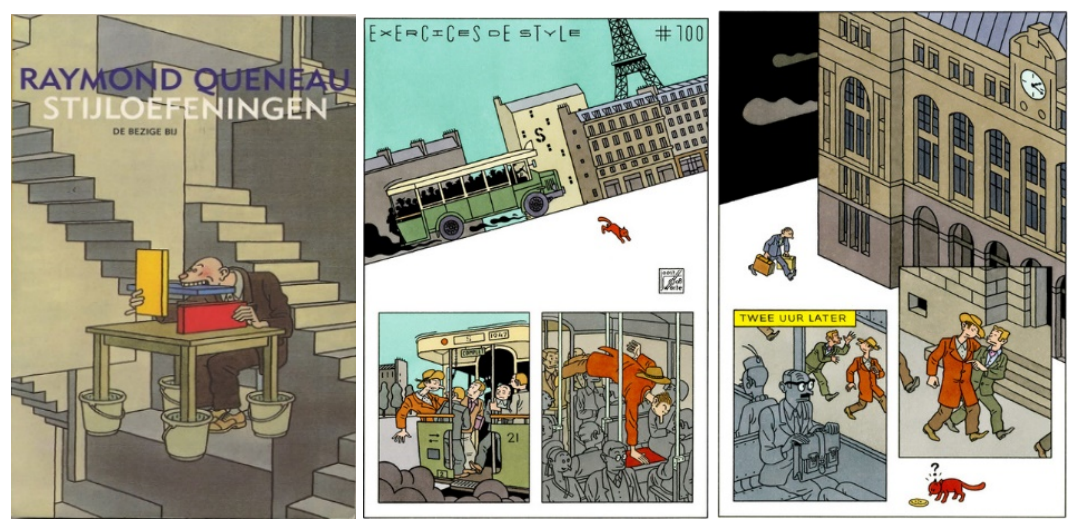

Matt Madden, a member of OuBaPo, added a new one to the practices of Exercises in Style on the visual platform by changing the story. In the graphic novel 99 Ways To Tell a Story: Exercises in Style, published in 2006, a simple one-page graphic story has been variated 99 times (Madden, 2006). Madden, with this work, investigates the ways of expressing with graphic novel medium and makes include in the game the stylistic features of this field, that differ in itself. In this sense, Madden also gives references to cult books and already known styles, using an Oulipian approach. Some of the variations consist of the titles of Queneau and some of the new constraints he produced for his medium (see: Figure 16). 


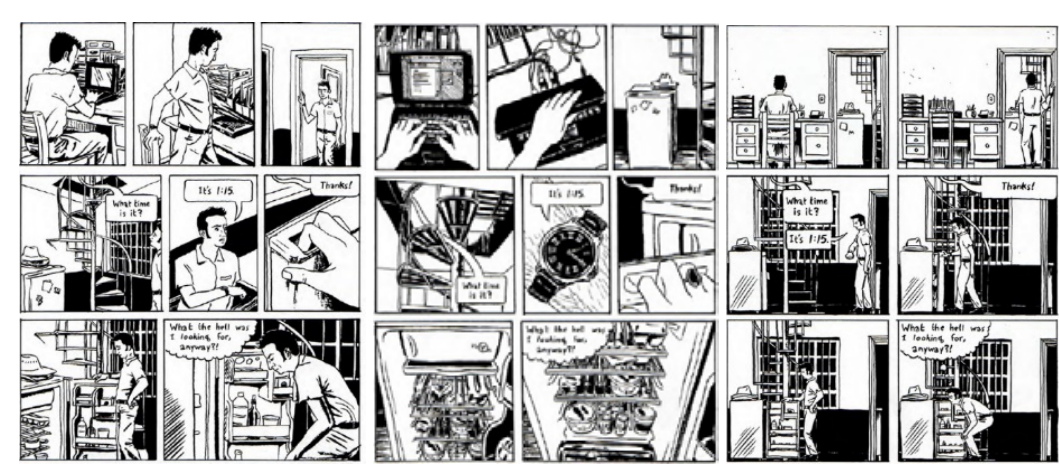

Similarly, Marcus Kraft published a 32-page newspaper in 2006. Also, this translation carried the story's expression into another medium where textual and visual expressions come together. Kraft interpreted Queneau's story like a piece of news in the newspaper and variated it with the opportunities of the newspaper (see: Figure 17). According to Kraft, the use of the newspaper is a remarkable medium in terms of showing how much news can be altered with different styles (Kraft, 2019).
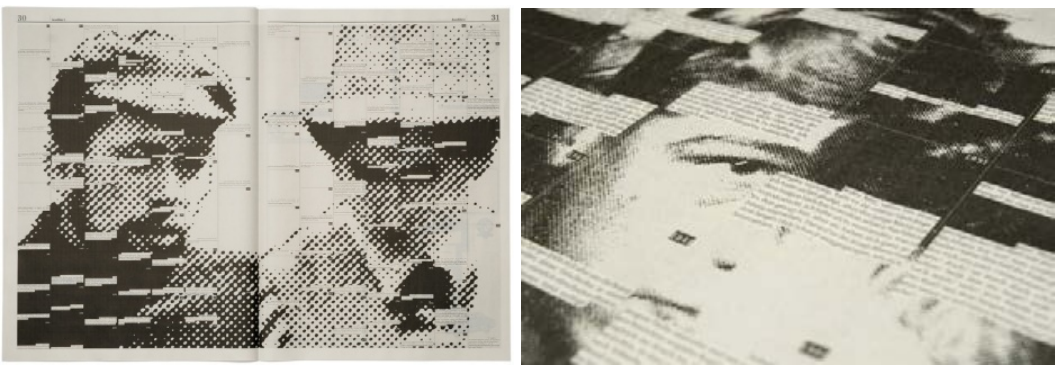

Another series concerning the graphic expression of the text was made by Monica Bengoa in 2015. Bengoa visualized the text in French, sometimes directly using original book pages through interventions to them, and sometimes by reproducing them without changing their content (Bengoa, 2019). In this context, the series he separated into groups for 99 variations, include representations, in which she altered the form of papers where the variations are written, and used the photography technique (see: Figure 18). The productions that Bengoa uses especially sewing and embroidery, can be considered as a reference to the word ouvroir that the name OuLiPo includes.
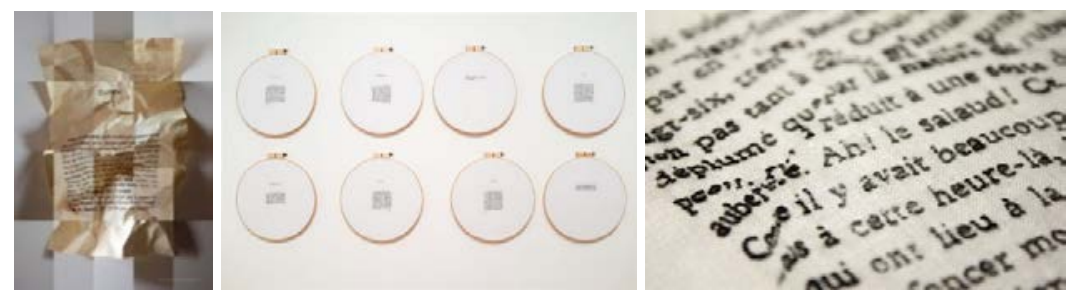

Figure 16. Variations titled Template, Subjective and Long Shots (Madden / 99 Ways to Tell a Stoy: Exercises in Style, 2006).

Figure 17. Examples of the newspaper sheets (Kraft) Stilubungen, 2006) (URL 4).

Figure 18. Variation representations created by the form given on the paper (Monica Bengoa, Exercices de Style, 2015) (URL 5). 
In addition to the translations concerning the representation of Exercises in Style, examples in which the text is applied with new stories and new techniques increase over time. In 2014, Christina Videira Lopes, with her book Exercises in Programming Style, presented 33 programming methods defined by constraints (Lopes, 2014). In the text entitled Exercises in criticism: The Theory and Practise of Literary Constraint published in 2015, critic and poet Luis Bury suggests that the apolitical texts created by early Oulipian writers should be turned into a means of cultural criticism. Within this context, regarding the constraining-based literature, it offers again constraining-based criticism methods (Bury, 2015). Perhaps, the most current translation of Exercises in Style was applied in the field of mathematics by Philip Ording in 2019 (see: Figure 19). With his work, 99 Variations on a Proof, Ording emphasizes the conceptual structure of mathematics and reveals research that questions the writing, reading, thus its form and stylistic features of mathematics (Ording, 2019). This study questions the relationship between mathematics and literature with an approach that can be performed from the reverse of OuLiPo.

Figure 19. Examples from cover and table of contents (Ording / 99 Variations on a Proof, 2019).

\begin{abstract}
11 In this study, 33 variations were made instead of 99 , in order to create an easily perceptible number. 33 is one of the symbolic numbers used in many adaptations of the text.
\end{abstract}

12 (Queneau, [1958] 1998).

13 (Queneau, [2003] 2010).

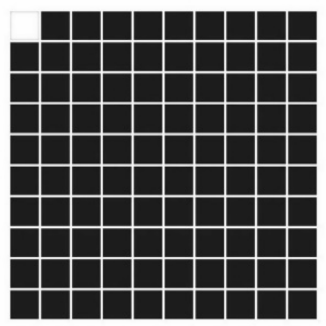

99 Variations on a Proof Philip Ording

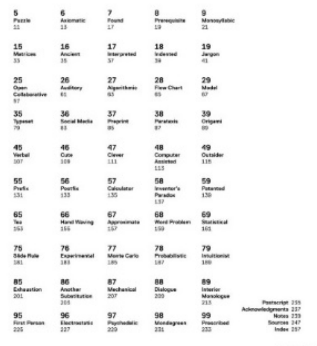

Translations of Exercises in Style include more than the examples presented here. This productive translation movement, which retains topicality, is similar to OuLiPo's enlarging network of OuXPo studies. Since its first publication, the work expands with its translations to languages other than French and all mediums other than the textual medium; constitutes a versatile dialogue. In other words, by creating an example of the Tower of Babel, it enables new experiments everywhere it reaches.

\section{VARIATIONS FOR SPACE}

In this study, 33 variations ${ }^{11}$ are tried for the space object, similar to the text Exercises in Style. The source text of this study, which can be defined as a kind of intersemiotic or interdisciplinary translation, is not only the original French text written by Raymond Queneau in 1947, but also the English translation 12 made by Barbara Wright and especially the Turkish translation ${ }^{13}$ made by Armağan Ekici. On the other hand, all the translations of the text in different disciplines, especially the 
graphic novel variations of Matt Madden, have been included as equivalent sources for the emergence of this work.

In the study, a template story is created similar to the original text and all other translations of it. It was paid attention to the fact that the fiction of this story to be in an insignificant and simple perception, as in the textual and visual mediums of both Queneau and Madden. Therefore, to create an equivalent fiction, the content of the story in the text is associated with the functional content of the space. ${ }^{14}$ The story in the text consists of two paragraphs and two particular actions are defined in two different contexts. Based on this, two different functions, namely working and resting, are defined in the template space produced. While making the variations of the space, although the organization and the form change for each iteration, the same attention has been given to the content that these functions are continued. The materials used for this fiction have also remained constant, but minor alterations and modifications are allowed in some exercises, depending on the constraint of the variation. The shell of the space is kept very neutral, and the moving elements in it are defined with the familiar and ready materials, based on the quotative approaches of OuLiPo. As in the original text, it is intended to produce variations that can be released even though the same content repeats every time. The first of the exercises, as in the original text, serves as a template for reference to others, with the Notation title (see: Figure 20).

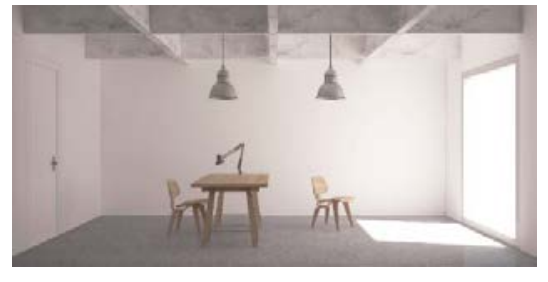

While the variations were being produced, some titles were borrowed from Queneau (through their English and Turkish translations), and some from Madden. In his translation, the exercises in which Madden adapted the constraints to his visual medium, have been a guide, especially for this translation to produce its spatial constraints and its titles.

The titles of the exercises, as in the original text, include significant information on the variation, as well as the theme of the spatial representation. The titles of some exercises retain the same expression, as they were based on the exercises written in the original text, while others are defined with new proposed title, as they are produced purely for the spatial production.
14 The final representations of the exercises were produced with different 2D and 3D CAD softwares that are frequently used in spatial production medium, as well as manual drawings. 
Exercise 2, titled Double Entry (see: Figure 21), derives its name directly from Exercises in Style; from the variation of secondperson narrative, the fiction is interpreted through the user effect on space. Variations named One and a Half (see: Figure 21) and Too Many Tables (see: Figure 23) are also derived exercises from this title and exaggerated and humoristic. In the exercise named Classroom (see: Figure 24), a situation in which that the language of the space, its function and identity can be altered by changing the positions of the elements in the space is displayed.

Figure 21. Exercise 2- Double Entry

Figure 1. Exercise 3- One and a Half

Figure 23. Exercise 4- Too Many Tables

Figure 2. Exercise 5- Classroom
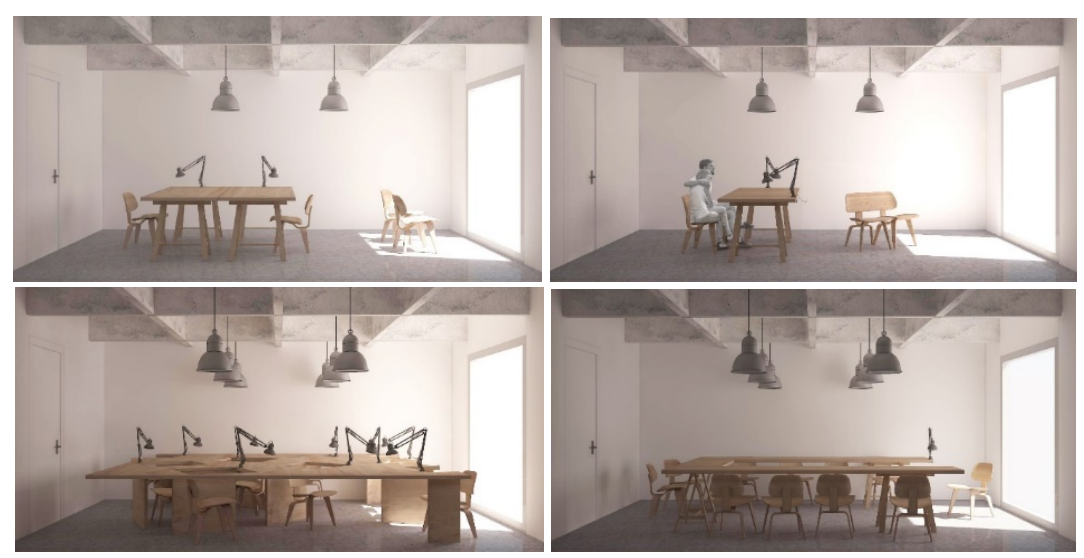

The exercise called Inventory (see: Figure 25) is an adaptation of one of the titles of Madden's translations. An inventory of structural elements and furnishings used in this space and its all variations has been revealed.

Figure 25. Exercise 6- Inventory

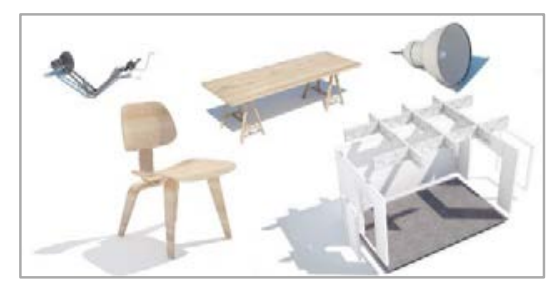

While the Three Fourths (see: Figure 26) exercise replies to one of the expected functions in a semi-open area, in the exercise Independent (see: Figure 27), the two functions in the fiction are solved in two separate areas. These variations refer to the perceptual effect of structural interventions at the space.

Figure 26. Exercise 7- Three Fourths

Figure 27. Exercise 8- Independent
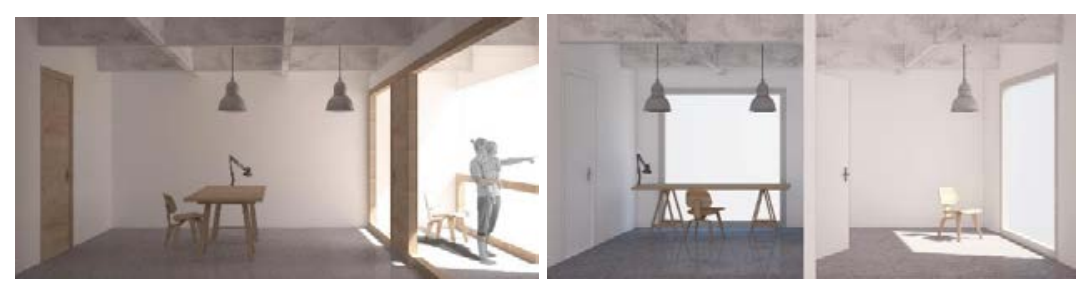
In some of the exercises, it is aimed to point out different representation methods used for space design. While being created an example for the hand-drawn representations of the space with Hand Made (see: Figure 28) titled exercise, in the variation named Software (3Ds Max) (see: Figure 29), the representation of the computer program used in this process is made visible. The title of the variation named Hesitation (Sketch) (see: Figure 30) is taken from Exercises in Style and the hesitative thinking style is interpreted by associating with the sketching process of spatial production. In another exerciserelated spatial representation, named Blueprint (Draft) (see: Figure 31), it is aimed to present one of the drawing types which gives information about the construction process of space.
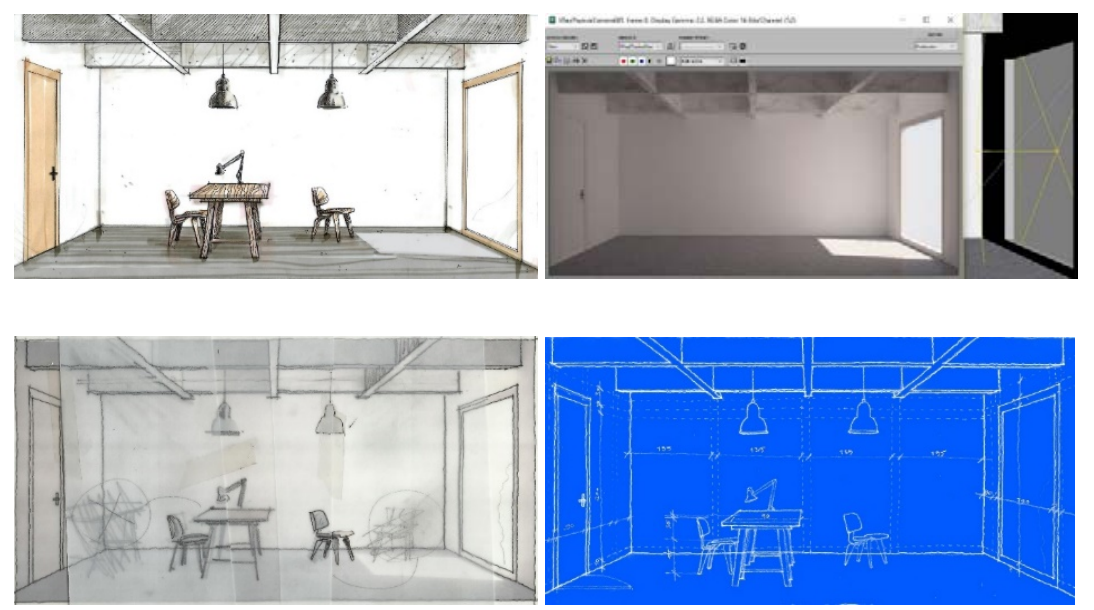

In another group of exercises, has got inspired by Lipogram and other similar Oulipian techniques that restrict a selected element. In the variation named Single Wall (see: Figure 32), the functions are obliged to be solved on a single wall, whereas in the variation called Foldaway (see: Figure 33), a second constraint introduced as the single wall is additionally turned into a single surface. In the exercise called Single Mass (see: Figure 34), both functions are solved with gaps opened in a single mass independent of space. Similarly, the exercise named Single Surface (see: Figure 35) shows the variation in which functions are solved by a surface effect that continues instead of mass. In the exercise named Hanging (see: Figure 36), the use of the floor is restricted, and the necessary functions are solved with the elements hanging from the ceiling. In the exercise called Bottom (see: Figure 37), an opposite constraint method is tried and using the areas except the floor is constrained. With these exercises, it is aimed to discuss the alternative styles that can be varied with the design strategy of the space.
Figure 28. Exercise 9- Hand Made Figure 29. Exercise 10-Software (3Ds Max)

Figure 30. Exercise 11- Hesitation (Sketch)

Figure 31. Exercise 12- Blueprint (Draft) 
Figure 32. Exercise 13- Single Wall Figure 33. Exercise 14- Foldaway

Figure 34. Exercise 15- Single Mass

Figure 35. Exercise 16- Single Surface

Figure 36. Exercise 17-Hanging Figure 37. Exercise 18- Bottom

Figure 38. Exercise 19Transparent

Figure 39. Exercise 20- Zoom Out (x)

Figure 40. Exercise 21- Zoom Out (2x)
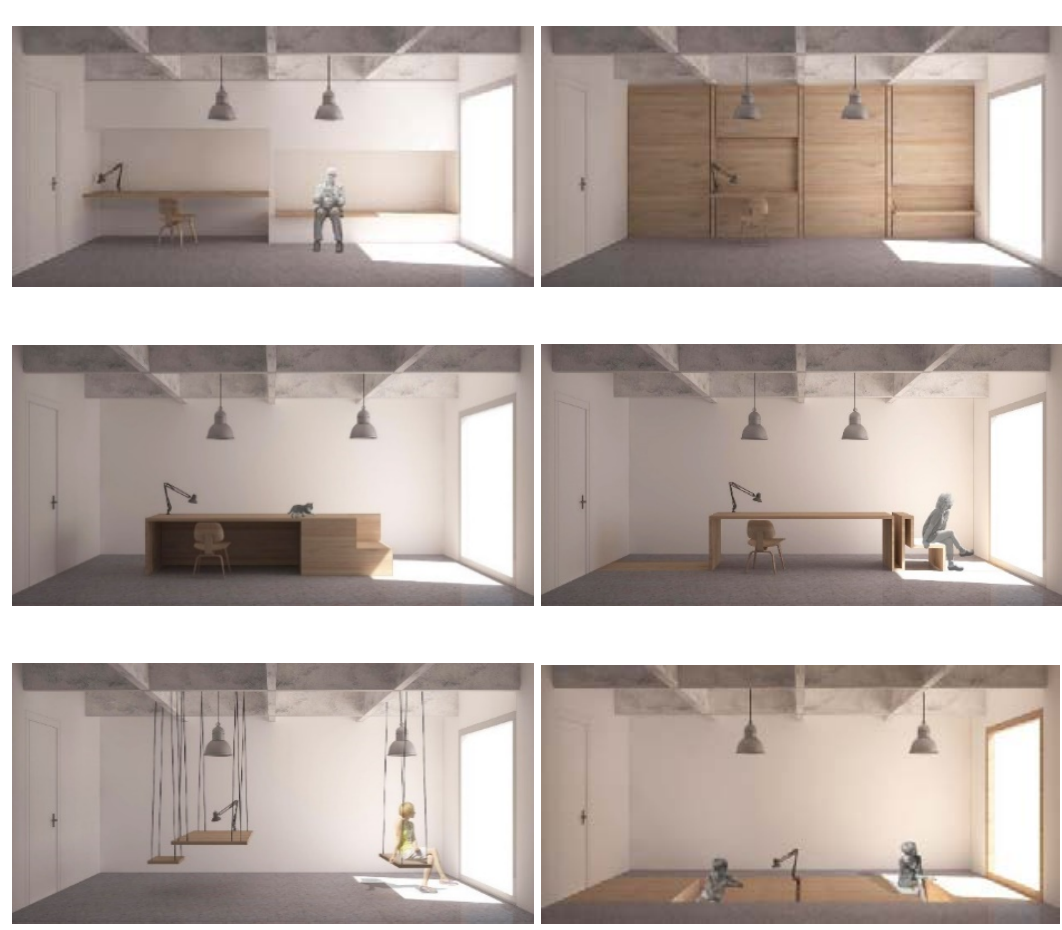

In the variation named Transparent (see: Figure 38), the walls in the space are eliminated, and the effects of the context to the space and to its atmosphere are highlighted. In the next two exercises with similar approaches, different scales are revealed and the direct effects of the context are investigated. In the exercise named Zoom Out (x) (see: Figure 39), the space is presented as a single building independent of its surroundings, while in the exercise named Zoom Out (2x) (see: Figure 40), the space is located within a multistorey building. Both exercises, were inspired from the variations of Madden.
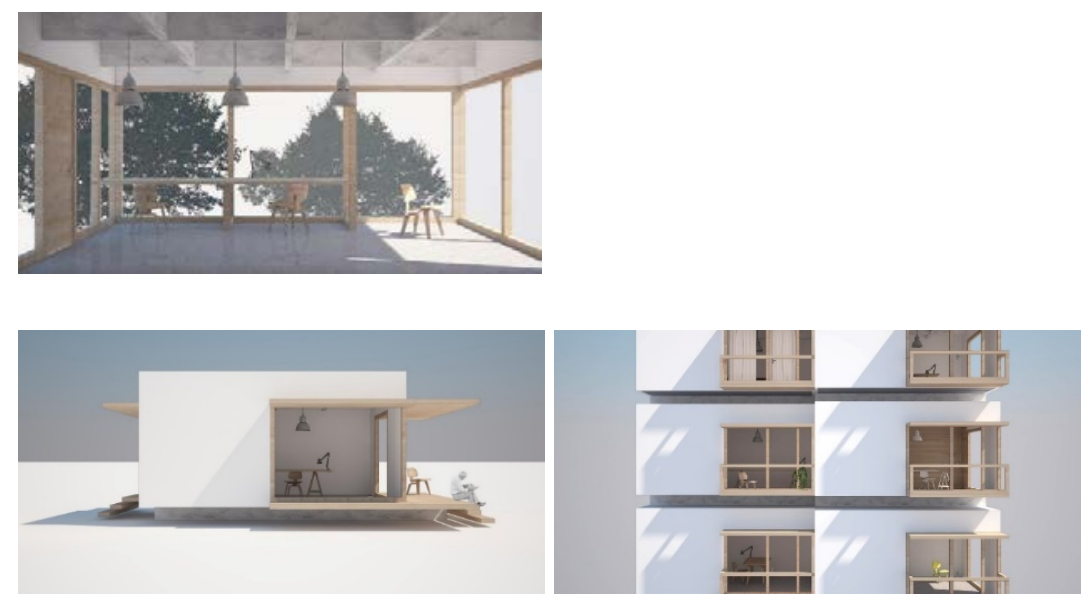

In the exercise named Window (see: Figure 41), an approach is fictionalized in which the existing spatial elements are manipulated by the window form. This exercise was inspired by the interfering techniques of OuLiPo and OuPeinPo. In the 
exercise titled Mezzanine (see: Figure 42), the function solutions are applied on only one surface and constrained with two different levels.
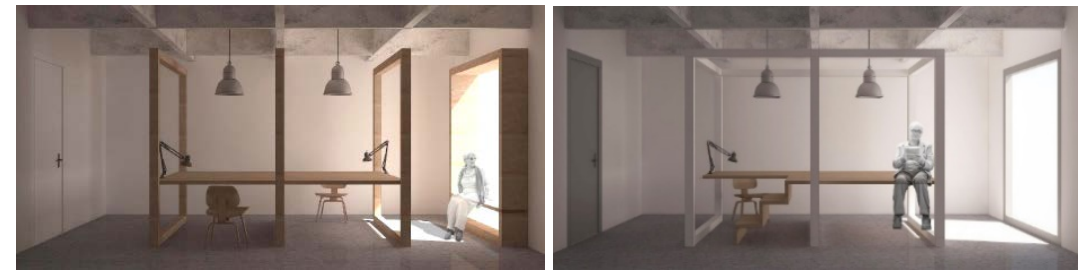

Ornate (see: Figure 43) is a title taken directly from Exercises in Style. This variation, in which Queneau made fun of exaggerated expressions of literature, is matched with similar approaches used in space representations. In addition, details referring to Raymond Queneau and Exercises in Style are used in the extra objects placed in the space. Similarly, in the exercise titled Young With a Long Neck and a Hat" (see: Figure 44), reference is made to the character in the original story with the visual figure used, it is also aimed to highlight human figures that make sense of spatial representations. In the exercise Cento (Hybrid) (see: Figure 45), the methods of representation using different techniques are brought together, inspired by the Oulipian Cento ${ }^{15}$ technique. In the exercise called The Gare Saint-Lazare (see: Figure 46), it is aimed to refer to the spatial context mentioned in the story in Exercises in Style, and also to include similar assembly methods used in spatial representations to the story.
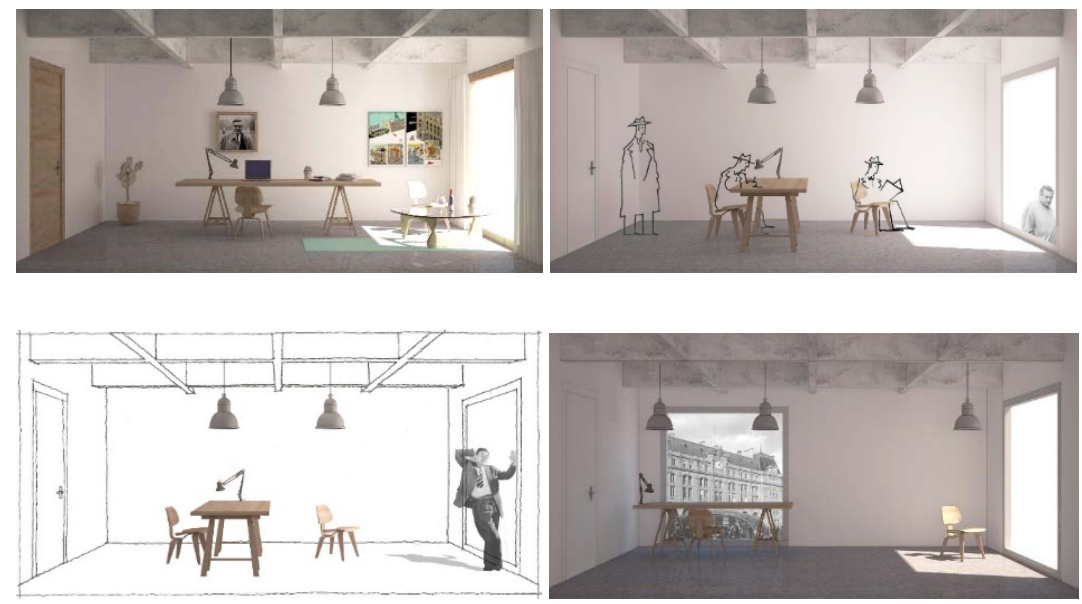

In some exercises, it has been inspired by OuLiPo's techniques that interfere with the fixed fiction. In the variation titled Reverse Space (see: Figure 47), the solution of functions is provided by inverting the fixed spatial organization fiction of all the other exercises. In the variation named Reverse Material (see: Figure 48), material decisions fixed in other exercises are reversed. In another exercise that has been inspired by one of the
Figure 41. Exercise 22- Window Figure 42. Figure 42: Exercise 23Mezzanine

15 Cento is an Oulipian poetry technique, also known as mosaic or patchwork, established with quotes from poems written in the past (Mathews \& Brotchie, 1998, p. 120).

Figure 43. Exercise 24- Ornate Figure 44. Exercise 25- "Young with a long neck and a hat"

Figure 45. Exercise 25- Cento (Hybrid)

Figure 46. Exercise 27- "The Gare Saint-Lazare" 
Figure 47. Exercise 28- Reverse Space

Figure 48. Exercise 48: Exercise 29-Reverse Material

Figure 49. Exercise 30- Colour

variations of Madden, in addition to the material in the space, the color factor is included in the game and it is titled as Colour (see: Figure 49).
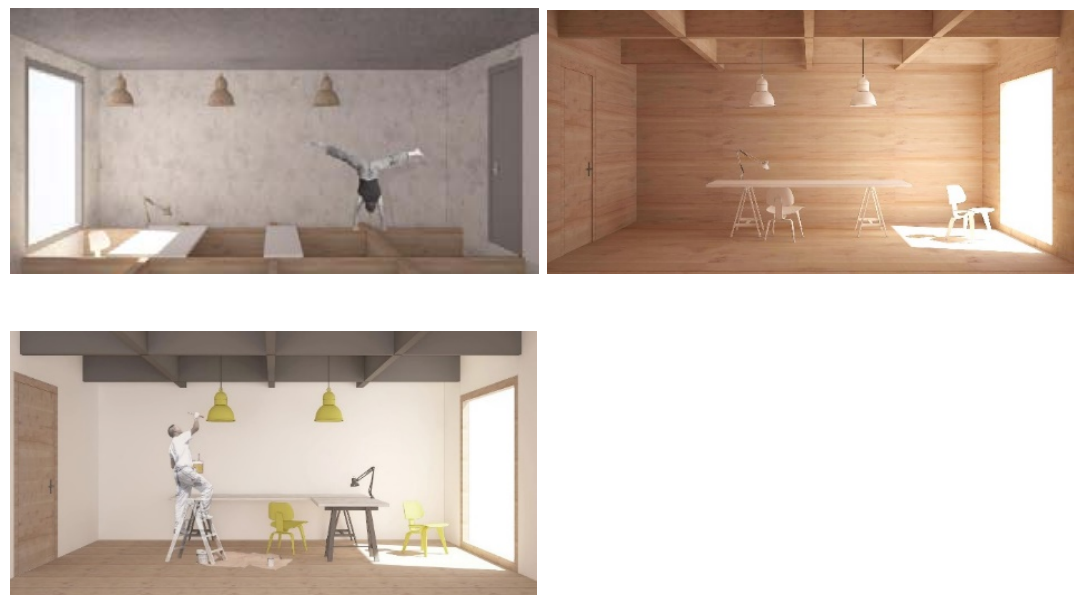

In the exercise named Grid (see: Figure 50), the aspects of Oulipian mathematical and formal methods, which are also valid in the design of the space, are tried to be emphasized. But in this variation, the grid which is a useful design tool is shown concretely in space with an opposite approach. It is aimed to create a playful sense that makes it impossible to use, with concrete grids used for carrying functional elements.

Figure 50. Exercise 31- Grid

16 See also: Haikutation, Io and the Wolf, End to end, Minimal Poetry, One-word poetry, One-letter poetry. Ref: (Mathews \& Brotchie, 1998).

Figure 51. Exercise 32- Table Savoye

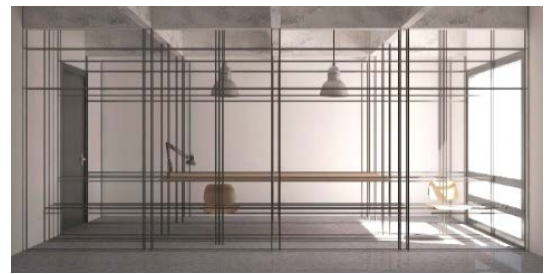

The exercise named Table Savoye (see: Figure 51) was inspired by some of OuLiPo's reducing techniques. ${ }^{16}$ Le Corbusier's wellknown building Villa Savoye has been readapted by carrying its certain characteristic features according to the functional program used in the process. This reference is tried to be emphasized with the title of the exercise and the Corbusier figure in the representation.

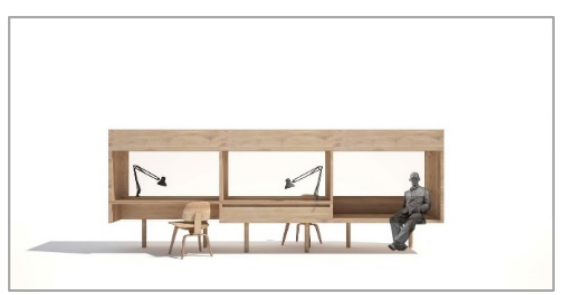


In the last exercise, an empty variation has been made that evokes the eternity as in Exercises in Style and many Oulipian works. With this variation called Tabula Rasa (see: Figure 52), it is aimed to emphasize the exhaustlessness of these translations and also to invite potential readers and translators to this game.

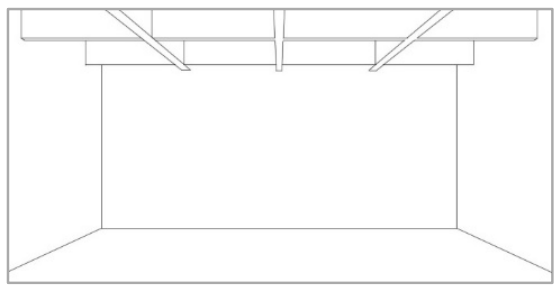

\section{CONCLUSION}

In this study, it is desired to be included in the game started by the Oulipian text, Exercises in Style, through the representation methods of the disciplines which design space. In this process, the "space object" has also been redefined as a linguistic structure, interpreted in a translation medium as a writable/designable canvas, both with its objectivity and its various representations.

In these exercises, beyond the purpose of solving a communication problem, it is desired to push the limits of the target language through the translation process. In this context, it is also a conscious choice to establish a dialogue between a distant discipline and architecture, and translate an Oulipian source text, to question the possibilities of spatial expression. In this translation, through which Exercises in Style is reproduced in another language, temporal context, and different discipline, the result also is naturally far from the fidelity sought in classical translation sense. Despite this variety, equivalent aspects have been found between linguistic and spatial expressions. The dynamic nature of the space object, which interacts with its designers, practitioners and potential users, has provided a linguistic medium suitable for a game in which a styling exercise is performed. On the other hand, since some of the variations made are produced in a different medium, it is required to adopt an appropriative method, while others, it is allowed to hybridize with preserving the strangeness of the original text. In these variations, the playful, absurd and strange sense seen in Oulipian texts is taken into consideration, and similar approaches especially are included.

In the variations in which the translation is close to the spatial medium, that space can impersonate different design approaches, are brought to the fore. In this context, in the space medium, besides the first variations that may come to mind, it was possible to present new design alternatives developed based
Figure 52. Exercise 33- Tabula Rasa 
on the original text. Also, some Oulipian techniques that reference the past have been adapted to the spatial production environment through similarities. In addition, OuLiPo's inclusion of quotations as a collage was another attitude that could come to the fore in terms of its closeness to the representation of space production. On the other hand, different expression methods required at different stages in design processes made it possible to produce additional variations. Therefore, every variation subsequently evoked another variation and created a fertile process. In addition, how Oulipian restriction methods triggered another unimaginable idea while forbidding something, have been experienced through this translation process.

This query made through these exercises has enabled multilayered readings, for the current and potential communicative possibilities of the spatial language, the transmission modes of spatial tendencies between times, the methods of expression of space medium, the restrictive factors in the design of the space, and the relationships that the spatial medium has established with other fields.

As a result of this experiment, a new translation was added next to many that keep the original text alive, as well as a sign of respect to Exercises in Style. However, this translation, of course, does not represent a completed product as in every translation. As in the attitudes of Oulipians and Ouxpians, the productions made in this study does not include any claim to be perfect result products, but it is aimed to point out the experience gained by the process. With the idea that the original text advocates, it is aimed to emphasize that these exercises can reach an infinite number and to obtain an open work that continues.

On the other hand, it is possible to produce many other alternative templates instead of the template space designed in this study. This fiction, made on the interior scale, may have other remarkable results at different scales. Instead of the sterile and imaginary fiction produced here, the variations to be made on a chosen tangible space may also be the subject of another exercise. Moreover, although the template space used here is represented on paper, given that space is a concrete place that is entered and experienced, the constraints and variations that may occur may be enriched and multiplied. This work created the first translation of the text in a spatial medium. However, this exercise aims to invite the potential trials of space-producing disciplines with OuLiPo constraints, just as Exercises in Style is a prototype of OuLiPo techniques.

Unlike searching for creativity with the expectation of spontaneous inspiration, Oulipian writers were able to discover endless potentials in situations where they came into existence by restricting their possibilities. Exercises in this area provide an 
experimental medium to improve creativity for space design in parallel with the purpose of OuLiPo. This translation experiment can be repeatedly edited for all kinds of educational activities, especially with its emphasis on exercise and repetition concepts, and creates an environment suitable for involving a large number of potential translators.

\section{ACKNOWLEDGMENT}

This paper is based on the Doctor of Fine Arts thesis entitled Space as a Translation Object And An Interdisciplinary Translation Study on the Text "Exercises in Style" at Hacettepe University in 2019.

\section{REFERENCES}

Akcan, E. (2012). Architecture in Translation: Germany, Turkey and the Modern House. London: Duke University Press.

Akdağ, A. I. (2010). Oulipo Teknikleri Çerçevesinde Bir Çeviri Çalışmasına Kültürel, Biçemsel ve Söylemsel Yaklaşım (Queneau'nun "Exercises de Style" Eserinin Türkçe Çevirisi); Master's Thesis. İstanbul: İstanbul Üniversitesi Sosyal Bilimler Enstitüsü Çeviribilim Anabilim Dal.

Akdağ, A. I. (2011). "Oulipo Metinlerinin Türkçe'ye Çevirisinin Olanakları: Yazın Dizgesinde Boşluğu Doldurma Aracı Olarak Deyiş Kaydırmaları", İ.Ü. Çeviribilim Dergisi; 2(3). Retrieved from http://dergipark.org.tr/en/pub/iuceviri/ issue $/ 1231 / 14425$

Aktulum, K. (2011). Metinlerarasıllk // Göstergelerarasıllk. Ankara: Kanguru Yayınları.

Barthes, R. (1989). "The Death of the Author", pp. 49-55 in $R$. Barthes, The Rustle of Language (R. Howard, Trans). Berkeley: University of California Press.

Becker, D. L. (2012). Many Subtle Channels: In Praise of Potential Literature. London: Harvard University Press.

Bengoa, M. (2019). Monica Bengoa. Retriewed from http://monicabengoa.cl/en/exhibicion/exercices-destyle-exercises-in-style-2/

Benjamin, W. ([1923] 2002). "The Task of the Translator", pp. 253-263 in W. Benjamin, Selected Writings Volume 1 1913-1926. London: The Belknap Press of Harvard University Press.

Benjamin, W. ([1982] 2018). "Tekniğin Olanaklarıyla Yeniden Üretilebildiği Çağda Sanat Yapıtı", pp. 50-87 in Pasajlar (A. Cemal, Trans.). İstanbul: Yapı Kredi Yayınları.

Bozdemir, Ö. A. (2018). "Yazının Anlatım Yolları", in Notos Öykü, 69 .

Brownholtz, B. M. (2013). Exercises in Style: 21st Century Remix: A Thesis Presented in Partial Fulfillment of the Requirements 
for the Degree of Masters of Arts. Chicago, Illinois: Department of English College of Liberal Arts and Social Sciences DePaul University.

Bury, L. (2015). Exercises in Critisism: The Theory and Practise of Literary Constraint. New York: Dalkey Archive Press.

Consenstein, P. (2002). Literary Memory, Consciousness, and the Group Oulipo. Amsterdam: Faux Titre.

Derrida, J. (1985). "Des Tours de Babel", pp.165-207 in J. Derrida, Difference in Translation (J. F. Graham, Trans.). Ithaca, London: Cornell University Press.

Dillon, S. (2017). Palimpsest. (F. B. Aydar, Trans.) İstanbul: Koç Üniversitesi Yayınları.

Eco, U. (2013). "Foreword", pp. 7-14 in R. Queneau Exercises in Style (B. Wright, Trans.). London: Alma Classics.

Edgü, F. (2015). Yazmak Eylemi: Bir Toplumsal / Siyasal Olay Üzerine 101 Çeşitleme. İstanbul: Sel Yayıncılık.

Ekici, A. (2016). Lacivert Taşından Tabletler. İstanbul: Everest Yayınları.

Elkin, L., \& Esposito, S. (2013). The End Of Oulipo? An Attemp To Exhaust A Movement. Winchester, Washington: Zero Books.

Grossman, E. (2010). Çeviri Neden Önemlidir? (A. Ece, Trans.) İstanbul: Yapı Kredi Yayınları.

İhsan, G. (2017). Kurmaca Alıştırmaları. İstanbul: Dergah Yayınları.

Jakobson, R. ([1959] 2012). "Çevirinin Dil(bilim)sel Özellikleri Üstüne", pp 61-66 in M. Rıfat Çeviri Seçkisi II: Çeviri(bilim) Nedir? İstanbul: Sel Yayıncılık.

Johnson, P., \& Wigley, M. (1988). Deconstructivist Architecture. New York: The Museum of Modern Art: Distributed by New York Graphic Society Books, Little Brown and Co.

Kraft, M. (2019). marcuskraft.net. Retriewed from: http://marcuskraft.net/portfolio/stiluebungen.html

Kristeva, J. (1966). Word, Dialogue and Novel. J. Kristeva içinde, The Kristeva Reader (pp. 35-61). New York: Columbia University Press.

Lopes, C. V. (2014). Exercises in Programming Style. CRC Press.

Madden, M. (2006). 99 Ways To Tell A Story. London: Jonathan Cape Publishing.

Madden, M. (2019). Matt Madden. Retriewed from: http://mattmadden.com/

Mathews, H. (2005). "Çeviri ve OuLiPo: Durmak Bilmeyen Maltız Vakası" (A. Ekici, Trans.), pp. 90-99 in Kitap-lık: 89.

Mathews, H., \& Brotchie, A. (1998). OuLiPo Compendium. London: Atlas Press.

Moors Magazine. (2019, Ocak 29). Retriewed from: https: //www.moorsmagazine.com/cartoons/swartequeneau/ 
Motte, W. (1998). OULIPO: A Primer of Potential Literature. Dalkey Archive Press.

Ording, P. (2019). 99 Variations on a Proof. Princeton University Press.

Özen, S. (2005). "OuLiPo'cular, Ou, Li ve Po'yu İleri Götürmek için Çalışırlar!", pp. 75-78 in Kitap-lık:89.

Paz, O. ([1971) 2012). "Söz Sanatı ve Söze Bağlılık Açısından Çeviri", pp.97-106 in M. Rifat, Çeviri Seçkisi II. İstanbul: Sel Yayıncilık.

Perec, G. (2003). "Günümüz Fransız Yazarlarının Güçleri ve Sinırları" (A. Derman, Trans.), pp. 68-72 in Kitap-lık:60.

Portzamparc, C. d., \& Sollers, P. (2014). Bir Mimar ile Bir Yazar Tartışıyor. (C. İleri, Trans.) İstanbul: Yapı Kredi Yayınları.

Queneau, R. ([2003] 2010). Biçem Alıştırmaları. (A. Ekici, Trans.) İstanbul: Sel Yayıncılık.

Queneau, R. (1947). Exercises de Style. Paris: Editions Gallimard.

Queneau, R. (1958). Exercises in Style. (B. Wright, Trans.) London: Gaberbocchus Press.

Queneau, R. ([1958] 1998). Exercises in Style. (B. Wright, Trans.) London: John Calder Publishers.

Queneau, R., Massin, R., \& Carelman, J. (1963). Exercices de Style. Paris: Editions Gallimard.

Read, A. G. (1998). "OuLiPo, Architecture, and the Practise of Creative Constraint". 86th ACSA Annual Meeting and Technology Conference, pp. 190-194, University of North Carolina at Charlotte.

Rıfat, M. (2008). "Daha İyi Anlamak İçin Daha Fazla Açıklamak İsteyen Bir Yorumbilimci: Paul Ricoeur", pp. 51-59 in Paul Ricoeur Cogito:56.

Symes, C. (1999). "Writing by Numbers: OuLiPo and the Creativity of Constraints" pp. 87-107 in Mosaic: An Interdisciplinarity Critical Journal, 32(3).

Şentürk, L. (2004). "Biçem Alıştırmaları ve Yazmak Eylemi", pp 171-181 in Geceyazısı, May 5.

Şentürk, L. (2016). "Konumlanmalar: Zümrüdüanka Projesi" in XXI: Oct. Retriewed from: https://xxi.com.tr/i/konumla nmalar-zumruduanka-projesi

Viers, C. A. (2008). The OULIPO and Art as Retrieval: Copyists and Translators in the Novels of Raymond Queneau, Italo Calvino, Harry Mathews and Georges Perec. PhD Dissertation. Los Angeles: University of California.

Wigley, M. (1989). The Translation of Architecture the Production of Babel. Assemblage, (8): 7-21.

Wittgenstein, L. ([1985] 2013). Tractatus-Logico Philosophicus. (M. Erşen, Trans.) İstanbul: Metis Yayıncılık. 
URL1: https://www.discogs.com/Raymond-Queneau-YvesRobert-Et-Sa-Compagnie-Les-Fr\%C3\%A8res-JacquesExercices-De-Style/master/552687

URL2: https://www.theatreonline.com/Spectacle/Exercices-destyle/54549

URL3: https://www.catawiki.com/l/647541-joost-swarte-raymo nd-queneau-exercises-de-style-100-diptych-2008

URL4: http://marcuskraft.net/portfolio/stiluebungen.html

URL5:http://monicabengoa.cl/en/obra/exercices-de-style-ejerci cios-de-estilo-photography/

\section{Resume}

Sirma Bilir; received her B.Arch (2009), MSc. (2013) and PhD (2019) from Department of Interior Architecure \& Environment Design, Hacettepe University. She is currently working as a Research Assistant at Hacettepe University.

Pelin Ylldız; received her B.Arch (1994), MSc. (1997) and PhD (2001) from Department of Interior Architecure \& Environment Design, Hacettepe University. She is currently working as a Professor at Hacettepe University. 